\title{
Oksana Kislaya
}

ORCID: 0000-0002-1362-9014

Narodowy Uniwersytet im. T. Szewczenki

Czernihów, Ukraina

\section{Технологии развития креативного мышления младших школьников с нарушениями зрения}

\author{
Techniques to develop creative thinking \\ of young learners with visual impairments
}

https://doi.org/10.34739/sn.2019.19.20

\begin{abstract}
The article states that the creation of conditions for the formation of an educated creative individual, the development of her/his spiritual-emotional and mental abilities, including creative thinking, is one of the strategic tasks of the whole system of education in Ukraine. The article covers the problems of creative development of children with visual impairment in the modern educational process and the development of creative thinking in such children as a powerful potential for their further effective socialization. Forming a creative person in general, and creative thinking in particular, means an implementation of the newest technologies (the method of synectics, brainstorming, theory of solving resourceful tasks, intellectual training, morphological analysis, a garland of associations) in the educational process of children with special educational needs. The effective development conditions of creative thinking of junior pupils are presented in the paper. An important role belongs to the conditions of family upbringing and the teacher, who should be an example for imitation.

Keywords: creativity, creative development, creative thinking, divergent thinking, junior school age, visual impairment

Аннотация: В статье утверждается, что создание условий для формирования образованного, творческого индивида, развития его / ее духовно-эмоциональных и психических способностей, в том числе творческого мышления, является одной из стратегических задач всей системы образования в Украине. В статье рассматриваются проблемы творческого развития детей с нарушениями зрения в процессе современного образовательного процесса, развития творческого мышления у таких детей как мощный потенциал их дальнейшей эффективной социализации. Способы формирования творческой личности, в целом и креативного мышления, в частности, подразумевают внедрение в процесс обучения детей с особыми образовательными потребностями новейших технологий (метод синектики, метод «брейнсторминга» (мозговой штурм), способы решения изобретательских задач, интеллектуальный
\end{abstract}


тренинг, морфологический анализ, гирлянда ассоциаций). Выявлены эффективные условия развития творческого мышления младших школьников. Важная роль принадлежит учителю, который должен быть примером для подражания, а также условиям семейного воспитания.

Ключевые слова: креативность, креативное развитие, креативное мышление, дивергентное мышление, младший школьный возраст, нарушения зрения

Современное общество требует быстрых изменений, новых прогрессивных, креативных идей, поэтому ценным сегодня является не столько репродуктивное мышление, которое важно в стабильное время, сколько продуктивное, творческое, созидательное мышление. В. Моляко отмечает, что сегодня, а тем более - завтра, именно творческая, эстетически обогащенная личность в состоянии решать как ежедневные производственные, так и масштабные задачи, которые будут обеспечивать не просто выживани, а прогресс нации [Моляко, 1995].

К проблеме формирования творческой личности общество обращалось на протяжении всей истории своего развития. Многие страны мира (Англия, Франция, США), осознавая перспективы исследования проблемы креативности и ее возможности, которые открываются в перспективе экономическому и социальному прогрессу, целенаправленно разрабатывают и внедряют инновационные образовательные программы, где доминантой является формирование креативного мышления.

Ориентация средней школы на репродуктивную деятельность часто приводит к тому, что большинство выпускников-отличников не умеют использовать полученные знания при решении жизненных ситуаций. Как следствие, на современном этапе жизни общества особой актуальности набирает задача развития креативности учащихся.

Социальный запрос на креативную личность отражен в законодательных актах по проблемам образования, в которых отмечается перспектива формирования неповторимого уникального человека, который способен творить. Как отмечается в Законе Украины «Об образовании», Национальной доктрине развития образования Украины в XXI веке, отраслевых стандартах высшего образования, Национальной стратегии развития образования в Украине на 2012-2021 гг. и других государственных документах, образование должно обеспечивать формирование у детей и молодежи не только системы знаний, научного мировоззрения, но и развитие их креативности, 
навыков самостоятельного научного познания, самообразования и самореализации школьников. Содержание Государственного стандарта начального общего образования и учебных программ отраслей образования не предусматривает изучение основ творческой деятельности. Однако высокий уровень (творческий) двенадцатибальной системы оценивания деятельности учащихся требует определения конкретных ориентиров, путей исследования динамики качественных изменений в овладении соответствующими умениями, которые были результатом овладения школьниками творческими практическими действиями. На современном этапе модернизации системы образования в Украине, внедрения положений НУШ (новой украинской школы) должен увеличиться удельный вес компонентов его содержания, обеспечивающих формирование креативных способностей личности. Целью образования детей с особыми образовательными потребностями должно стать проблемное обучение, внедрение в образовательный процесс инновационных технологий (новых методов, средств и форм обучения), которые способствуют креативному развитию личности.

Ученые все больше сходятся во мнении о том, что способность к творчеству характеризует всех людей, а не только выдающихся деятелей науки, техники и культуры, ее можно стимулировать и развивать целенаправленно, повышая производительность человека. Концепции воспитания личности должны быть тесно связаны с ведущими тенденциями, определяющими прогрессивное развитие человечества, опираются на творческий потенциал человеческой личности и влияют на ее дальнейшее становление. Современное состояние исследования творчества можно охарактеризовать как процесс сближения двух подходов: процессуального - исследование фаз, состояний, стадий и результатов преобразования предмета творчества и личностного - исследование субъекта творческой деятельности - его потребностей, мотивов, знаний, умений, навыков, самосознания, эмоций, чувств (Д. Богоявленская, Л. Выготский, В. Давыдов, Д. Эльконин, Г.Костюк, В. Мерлин, В. Моляко, В.Рибалка, В. Русалов, М. Холодная, В. Юркевич и др.).

Одни психологи считают понятие «творческие способности» и «креативность» подобными и утверждают, что креативность является самостоятельным фактором и не зависит от интеллекта (Дж. Гилфорд, К. Тейлор, Г. Грубер, Я. Пономарев, Е. Торренс и другие), другие считают, 
что высокий уровень развития интеллекта предполагает высокий уровень развития творческих способностей и наоборот (Д. Векслер, Р. Уайсберг, Г. Айзенк, Л. Термен, Р. Стенбергт и др.), по мнению третьих, творческих способностей не существует, главную роль в детерминации творчества играют мотивация, ценности, эмоциональное состояние и др. (А. Танненбаум, А. Олох, Д. Богоявленская, А. Маслоу и др.). Методологическое обоснование современных методов организации творческой деятельности отображено в трудах таких исследователей, как А. Антонов, Д. Берлайн, А. Брушлинский, Т. Кудрявцев, О. Матюшкин, Е. Милерян, А. Есаулов, И. Якиманская и др.

Творчество рассматривается как основа и механизм развития психики (Н. Кипиани, Я. Пономарев, И. Семенов и другие), а его исследования предполагают рассмотрение закономерностей мышления (Н. Алексеев, С. Бернштейн, В. Библер, О. Тихомиров, Э. Юдин). Творчество является тем мостиком, через который проходит эмоционально эстетическая реакция от восприятия к воспроизведению и закрепляется как личностное новообразование. Поскольку под понятием творчества в начальной школе мы подразумеваем не создание духовных ценностей, не конечный результат, а сам процесс, способность к перевоплощению чужих мыслей и чувств в свои собственные, то вся деятельность ученика почти полностью должна быть творческой.

Учитывая подход ученых (В. Клименко, И. Лернер, В. Сухомлинский, Н. Юхимчук и другие) определено, что полноценное развитие креативности необходимо начинать с младшего школьного возраста, так как именно этот возрастной период является сенситивным для ее развития. Это время, когда спонтанное и, часто, репродуктивное творчество дошкольного возраста соединяется с быстро растущим интеллектом, абстрактным мышлением, логичностью. В этом возрасте существенно возрастает возможность самостоятельной постановки целей, мотивирование себя, поиска способов действий и контроля результатов. Поскольку для учеников начальной школы шаблонные, стереотипные формы мышления и действия еще не стали доминантными, становится возможным интенсивное усвоение ими креативных способов деятельности, сложных мыслительных операций и форм поведения, которые требуют творческой деятельности. Обучение творчеству для младшего школьника аналогично обучению чтению письму, счету. Готовность учащихся к поиску нового, неизвестного, 
желание действовать, высокая адаптивность находят подтверждение в технологиях: развивающего обучения (В. Давыдов, Д. Эльконин, Л. Занков) творческой самореализации личности (И. Волков, Е. Ильин), проектной (Дж. Дьюи), интерактивной (А. Пометун). Развития креативности личности в процессе обучения способствуют присущие младшим школьникам открытость ко всему новому, любознательность, эмоциональность, целостность восприятия, яркое воображение, образность мышления, активное позитивное отношение к действительности, что их окружает. Младший школьный возраст - сенситивный период для развития креативности учащихся, поскольку является периодом бурных процессов преобразований в физиологии и психике личности [Выготский Л., 1991]. Ключевая роль в развитии креативности младших школьников принадлежит школе и учителям начальных классов.

Исследования многих ученых в области тифлопедагогики и тифлопсихологии (Л. Вавин, М. Земцова, А. Литвак, И. Моргулис, С. Покутнева, Е. Синева, Л. Солнцева и др.) доказали, что нарушения зрения негативно влияют на развитие и формирование личности в целом. Известно, что нарушения зрительного анализатора влияют и на проявления творческой активности, но коррекционно направленное стимулирование творческих способностей, креативности, как категории мышления, активное включение детей со сниженным зрением в эстетически-творческую деятельность в урочное и внеурочное время имеет положительный результат.

Проблема развития креативности детей с нарушением зрения до последнего времени разрабатывалась недостаточно. Кроме того, мало исследованным остается вопрос феномена креативности как мощного компенсаторно-коррекционного потенциала в развитии, становлении, социализации личности детей со сниженным зрением.

Целью статьи является раскрыть современные технологии (методы, средства и формы обучения), которые будут способствовать развитию креативного мышления у детей с нарушениями зрения; определить условия развития креативного мышления.

Сейчас в научной среде активно происходит пересмотр теоретических позиций относительно природы творчества, критериев диагностики творческих способностей и творческого мышления, ведутся научные исследования источников такого феномена как креативность 
и условий, способствующих развитию креативности. Для успешного решения этих проблем необходимо искать принципиально новые технологии обучения. Проблема развития у детей с нарушениями зрения креативности, дивергентного мышления является одной из актуальных проблем.

Проблема развития креативности младших школьников касается огромного спектра вопросов, связанных с феноменом развития личности. Проведенный анализ показывает, что креативность и творческая деятельность взаимосвязанные понятия. Творческая деятельность является фундаментом, предпосылкой развития креативности, целью развития личности. В учебном процессе творческая деятельность учащихся выступает как организованная учителем учебно-творческая или творчески познавательная деятельность. Креативность младшего школьника является сложным синтетическим понятием. Развитие креативности связано с созданием нового, оригинального продукта в процессе учебно-творческой деятельности. Креативность младшего школьника, по определению Т. Воробьевой - это общая характеристика личности ученика, которая проявляется, прежде всего, в учебнопознавательной деятельности и обуславливает творческую направленность ребенка, его способность к самостоятельному выбору оптимального и оригинального пути решения учебных задач, создание новых идей, продуктов, новизна которых может быть как объективной, так и субъективной [Воробьева, 2014, с. 6].

Креативность - это интегративная, динамическая личностная характеристика, определяющая способность к творчеству и является одним из условий самореализации личности. Ее основным процессом является дивергентное мышление. Творческие способности или креативность - явление многокомпонентное, которое тесно связано с личностными и мотивационными изменениями.

Ядро креативности ученика начальной школы образуют креативные способности, которые являются составляющей общих способностей личности и проявляются в творческом подходе к учебнопознавательной деятельности, познавательной активности, критичности и тому подобное. Креативные способности младшего школьника - это комплекс индивидуально-психологических особенностей, обусловливающих способность ученика успешно осуществлять учебно-творческую деятельность. Они раскрываются и развиваются в процессе этой же 
учебно-творческой деятельности. Анализ значительного количества источников свидетельствует, что под способностями понимают синтез свойств, обусловливающих успешное выполнение деятельности, в частности креативной. Они развиваются на основе врожденных задатков индивида в определенной образовательной среде [Габеркорн, 2013, с. 7].

В структуре креативных способностей ученые выделяют такие компоненты: дивергентное мышление (Г. Альтшуллер, Дж. Гилфорд, В.Моляко, Г. Терехова), способность генерировать большое количество идей (Н. Барышева, Дж. Гилфорд), творческую мотивацию (А. Матюшкин), вдохновение (В. Роменец), владение приемами творчества (Г. Терехова, С. Гон) и др. По мнению ученых основными креативными способностями учащихся, которые могут быть развиты в процессе обучения, является креативный интерес, креативное мышление, воображение и интуиция; энергопотенциал, психомоторика, мышление, воображение и чувства [Середа, 2011, с. 1].

T. Воробьева определяет компонентный состав креативных способностей детей начальной школы: продуктивное воображение, креативное мышление (сочетание элементов творческого и критического мышления), информационная грамотность [Воробьева, 2014 ].

В отечественной и зарубежной психологии и педагогике разработаны и внедряются различные программы и методы развития креативности (В. Дружинин, В.Моляко, А. Туник, Н. Хазратова, А. Яковлева). Первые методы развития креативного мышления были разработаны Дж. Гилфорд, Э. Де Боно, Р. Крачфилд, Е. Торренс и получили широкое применение в школьной практике. Среди новых методов стимулирования креативности наибольшее внимание привлекают методы синектики, метод «брейнсторминга» (мозговой штурм), ТРИЗ (способы решения изобретательских задач), морфологического анализа, конференция идей, гирлянда ассоциаций. Одним из эффективных путей развития дивергентного мышления являются различные формы интеллектуальных тренингов, игры, исследования.

Первая методика по развитию креативного мышления была разработана Р. Крачфилд. Исследователь считал, что креативность может быть развита в процессе решения творческих задач. Своим ученикам он предлагал прочитать небольшие книги (16-20 страниц в каждой), где 
рассказывалось о приключениях двух подростков, которым постоянно приходилось разбираться в детективных историях. В процессе поиска герои-подростки выдвигали неожиданные версии, им неоднократно приходилось менять свои предположения о событии, прежде чем появлялась правильная версия. Кроме того, в рассказах содержалось много советов по развитию креативного мышления. Проведенный Р. Крачфилдом эксперимент показал, что ученики из экспериментальной группы сумели решить в три раза больше задач, чем ученики контрольной группы, причем достигнутый эффект сохранялся в течение 6 месяцев.

Е. Торренс предложил поэтапную систему развития творческого мышления [1988]. На первом этапе ребенку предлагаются задания и он очень быстро должен выделить среди множества гипотез одну правильную, сформулировать правило, которое привело к разгадке проблемы. Затем ребенку предлагается рассмотреть рисунки. Он должен назвать различные, даже невероятные причины, которые привели к этой ситуации, и ее последствия. На втором этапе ребенку предоставляются предметы и предлагается перечислить различные способы их применения.

Американский психолог Э. Боно предложил программу развития креативного мышления на основе пяти принципов [Боно, 2005]. Первый принцип заключается в том, что при возникновении проблемы важно выделить необходимые и достаточные условия ее решения. Если использовать все предложенные условия без определения их необходимости в данной ситуации, то можно усложнить процесс решения проблемы. Второй принцип - необходимо выработать установку на отвержение своего прошлого опыта, полученного при решении подобных проблем. Третий принцип - необходимо развивать умение видеть многофункциональность вещей. Четвертый принцип формирование умения сочетать противоположные идеи из разных областей знаний и использовать такие «соединения» для решения проблем. Пятый принцип - развитие способности к осознанию многогранности идеи в данной области знаний и освобождение от ее воздействия при решении конкретной проблемы. Э. Боно разработал набор приемов, которые способствуют развитию дивергентного мышления: функциональный и структурный анализ. 
Педагогами и психологами разработаны различные методы развития креативности у школьников. Самым популярным в наше время является метод проблемного обучения, разработанный М. Махмутовым. Целью метода является усвоение учащимися предметного материала путем решения специальных познавательных задач-проблем и моделирования проблемных ситуаций [М. Махмутов, 1975].

Следующий вид креативных методов - метод эвристики. Это приемы, которые позволяют учащимся решать вопросы путем «наведения» на возможные правильные решения и сокращения вариантов таких решений. А. Хуторской предложил эвристическое обучение, которое характеризуется тем, что из процесса обучения почти исключены репродуктивные элементы деятельности [Хуторской, 2000]. Целью метода является не только развитие креативности и дивергентного мышления ученика, но и стремление сделать его субъектом и конструктором своего образования, организатором своих знаний.

В дидактике используют много методов развития творческого мышления, которые называются проблемно-активизирующими методами. Применение их в учебно-воспитательном процессе, безусловно, будет способствовать развитию креативного мышления детей с нарушениями зрения.

Среди различных методов, используемых в процессе креативного обучения, главное место занимают исследовательский и частичнопоисковый. В этом плане довольно интересна технология обучения, предложенная А. Сологуб. По мнению автора, креативная направленность образовательного процесса предполагает развитие дивергентного мышления учащихся благодаря привлечению их к активному исследованию и формированию творческого (продуктивного) стиля деятельности, проявления креативных черт личности [Сологуб, 2006, с. 4-5]. Учитель побуждает школьников к максимальной познавательной активности. Он создает творческий психологический климат средствами сотрудничества с учениками. Главное отличие между креативным и развивающим обучением, по мнению А. Сологуб, заключается в том, что креативное обучение способствует развитию как интеллектуальных, так и креативных способностей личности, а развивающее - только интеллектуальных.

Известный украинский психолог В.Моляко считает, что в вопросе о развитии креативности не может идти речь об алгоритмах, стандартных 
приемах, способах и методах, а, в первую очередь, нужно формировать стратегию. В. Моляко предлагает созданную им систему, которая одновременно имеет диагностическую и тренировочную направленность - КАРУС (аббревиатура от слов комбинирование - аналогизирование - реконструирование - универсальный подход - ситуативное поведение (попытки решать задачи как угодно)) [Моляко, 1995].

Другой вид креативных методов обучения базируется на использовании алгоритмических предписаний и инструкций (метод синектики, «морфологического анализа»). Их цель - построение логической опоры для создания учениками образовательной продукции.

К креативным методам относятся также:

- метод сочинения - способ создания неизвестного ученикам ранее продукта по результатам определенных умственных действий;

- метод «Если бы ...» - учащимся предлагается составить описание и нарисовать рисунок того, что произойдет, если в мире что-то изменится. Выполнение подобных задач не только развивает способность представлять, но и позволяет лучше понять строение реального мира, взаимосвязь его составляющих, фундаментальные основы различных наук;

- метод образной картины. Ученик во время такой работы не только думает разными масштабами, соотносит свои знания из различных областей знаний, но и чувствует значение изображенной реальности;

- гиперболизация - увеличивается или уменьшается объект познания, его отдельные части или качества;

- аглюцинация - ученикам предлагается совместить несочетаемое в реальном мире, например, горячий снег, сладкую соль и др.

Итак, технологии развития креативности (проблемные, когнитивно-эвристические, креативные арт-технологии) в наибольшей степени соответствуют природе творчества. Их задачей является развитие комплекса креативных свойств личности, приобретение опыта продуктивной (творческой) деятельности в результате дивергентного мышления на основе самопознания и саморазвития.

Теория и практика тифлопсихологии доказали, что нарушения зрения, в целом негативно отражаясь на активности человека, влияют 
и на проявление творческой активности. Доказано, что коррекционно направленная стимуляция творческих способностей у детей с нарушениями зрения имеет положительные результаты (Е. Синева [Синева, 2008]). Известно, что в процессе творческой деятельности детей с нарушениями зрения происходит развитие творческой активности, креативных способностей, сохранных анализаторов (слуха, обоняния, осязания и др.) Формирование навыков и способов восприятия и воспроизведения предметов и явлений окружающего мира, раскрытие всех коррекционно компенсаторных возможностей такого ребенка (Л. Куненко, Л. Нафикова [Куненко, 2000, Нафикова, 2008]). Эстетическитворческая деятельность имеет коррекционное влияние на развитие личности ребенка с нарушением зрения, поскольку у ребенка развиваются восприятие, чувства, креативное мышление, воображение, творческие способности, уверенность в своих силах, что помогает ребенку с нарушениями зрительного анализатора чувствовать себя увереннее, развиваются ее коммуникативные способности и т.п. Различные виды искусства (музыка, изобразительное искусство, скульптура, литература и т.п.) на соответствующих уроках или во внеурочное время, оказывают огромное влияние на личность ребенка с нарушением зрения, ее дальнейшее развитие, становление и социализацию.

Так, используя методы развития креативности у таких детей, например, в процессе эстетической творческой деятельности и во внеурочное время, можно научить детей алгоритму выхода из проблемных ситуаций, легко переносить опыт решения проблемных ситуаций на другие задачи, быстро воспроизводить в памяти знания, необходимые для решения новых задач, генерировать оригинальные идеи, всегда быть готовыми к мобилизации интеллектуальных сил, к преодолению препятствий, к применению интуиции, к проявлению оригинальности в решениях, выработать в учащихся способность разносторонне мыслить.

Развитие творческих способностей у детей с нарушениями зрения может быть эффективным, если в организации творческой деятельности использовать творческие задания открытого» типа, дивергентные задачи, задания, адаптированные возрастным особенностям ребенка и для детей с нарушениями зрительного анализатора; организовывать разнообразную деятельность на основе творческого сотрудничества. 
Задачи дивергентного типа крайне редко используются в традиционном школьном обучении, тем более в обучении детей с нарушениями зрения. Классическое образование обычно не ставит целью развитие креативной личности и навыков творческого, нестандартного мышления, В связи с чем дивергентные задачи приобретают особую ценность.

В ходе выполнения задач дивергентного типа у детей с нарушениями зрения развиваются такие качества креативного мышления, как оригинальность, гибкость, легкость ассоциирования и другие качества и способности, необходимые в творческой деятельности.

Анализ учебников (дети с нарушениями зрения занимаются по учебникам общеобразовательной школы) доказал, что целью большинства задач является формирование умения решать конвергентные задачи, то есть имеющие однозначный и единый правильный ответ. Такие задачи не эффективны по развитию креативного мышления ребенка. Напротив, дивергентные задачи предусматривают, во-первых, отсутствие готовой схемы решения, или задачу нельзя решить известными способами по схеме, во-вторых, к решению невозможно прийти на основе прямого воспроизведения знаний, имеющийся опыт необходимо творчески переработать. K дивергентным задачам относятся также задания на развитие креативного мышления у детей, например, сочинение рассказов, историй или сказок, используя заданный набор слов.

Итак, дивергентные задачи имеют такие особенности: отсутствие однозначного готового ответа; необходимость создания значительного количества вариантов; направленность ученика на нахождение особых, часто неожиданных результатов; наличие нескольких правильных альтернативных ответов.

Мы считаем, что творческие задачи и задания можно предлагать детям с нарушениями зрения не только в процессе эстетической творческой деятельности, но и на уроках математики, природоведения, родного языка и т.п.

Для оптимального развития креативного мышления следует создать условия. Создание таких условий зависит от учителя. Но роль учителя в данном процессе не ограничивается только созданием психологического климата. Она заключается еще и в том, чтобы активно 
помочь ребенку в развитии его креативности. Дж. Гилфорд утверждает, что развитие креативности станет возможным, если будут созданы такие основные условия: создавать благоприятную атмосферу для развития креативности; не критиковать ребенка; способствовать свободному развитию разнонаправленного мышления; обогащать среду ребенка; удовлетворять любопытство; помогать формулировать оригинальные идеи; обеспечить возможность для использования новых идей на практике; показывать личный пример креативного подхода к решению проблемы; позволять детям активно задавать вопросы [Гатанов, 1996]. Именно в начальной школе должны быть созданы благоприятные условия для всестороннего развития учащихся, раскрытие их склонностей и способностей.

Существенным условием развития креативности детей в учебновоспитательном процессе является развитие самостоятельности, поскольку творческая деятельность человека предполагает самостоятельное создание новых, оригинальных продуктов. Тем не менее, не каждый вид деятельности развивает креативность. Центральное место в творчестве следует предоставить самостоятельной продуктивной деятельности учащихся, направленной на получение нового результата. В отношении учащихся начальных классов, то их инновационная творческая деятельность должна быть направлена не столько на технические решения, как на решение реальной задачи: составление задач, загадок; формулировка гипотезы; создание сказки, метафоры, пословицы; разработка игры; описание новых свойств объекта и его практического применения; поиск вариантов задания; решение технических и социальных проблем; изготовление игрушек, рукоделие и т.д.

Важную роль в развитии креативности в учебно-воспитательном процессе играет подражания учениками креативной деятельности учителя. Педагог должен обладать такими креативными возможностями: креативным воображением и мышлением, развитыми чувствами и высоким уровнем работоспособности. Е. Торренс первым заметил, что причиной торможения креативной деятельности учащихся является неправильная позиция учителя. Он выработал требование к учителям по развитию креативного мышления - это, прежде всего, открытость к вопросам учеников. Учитель должен слушать даже странные, по его мнению, вопросы и адекватно реагировать на них; необычные идеи, 
которые возникают в ходе занятия, учитель должен поддержать, а не критиковать; давать детям почувствовать, что каждая идея является важной и ценной; не осуждать работу учащихся, это способствует появлению оригинальных идей; оценка учителем должна всегда быть обоснована. Учитель должен точно определить, что данная идея интересна и она приносит положительные результаты [Торренс, 1988, с. 146]. Соблюдение этих требований в сочетании с положительной атмосферой в классе, где учитель является координатором урока, готов помочь каждому ребенку, укрепляет веру в возможности учащихся. Ученые-педагоги предпочитают демократический стиль преподавания, поскольку дети чаще задают вопрос учителю, чем при авторитарном стиле. Не менее важным является тот факт, что создание благоприятной среды для творческих детей приводит к изменению социального статуса ученика и это позволяет изменить значение «градации» всех учеников в классе, повысить престиж креативного мышления, а это, в свою очередь, влияет на развитие креативности всех учеников. На развитие креативности ребенка влияют стили семейного воспитания. Для повышения степени проявления у ребенка креативности необходимо родителям дать ребенку возможность делать выбор самостоятельно (дать ему психологическую свободу), повышать его самооценку, снижать наказание за поступки и всячески поддерживать его исследовательскую активность. Креативность развивается у ребенка тогда, когда ему при решении задач не дают инструкции и образца действий. Нельзя достичь результатов в развитии креативности, если человек не имеет волевых качеств, внутренней выдержки. Креативность является следствием проявления сильных личностных качеств, таких как умение противостоять мнению большинства, добиваться реализации поставленных целей и побеждать в борьбе.

Таким образом, использование в образовательном процессе школ для детей с нарушением зрения новейших технологий (методов, средств) формирования креативности, в том числе творческих заданий, дивергентных задач обеспечит эффективное развитие креативности таких детей, а именно будет способствовать формированию дивергентного мышления, значительно улучшит их социализацию и поставит на новый уровень познавательную и социальную активность детей с нарушением зрения. 


\section{Literatura [Литература]}

Bono E., (2005), Nauchitesebya dumat': samouchitel' po razvitiyu myshleniya, ООО «Popurri», Minsk, [Боно Э., (2005), Научите себя думать: самоучитель по развитию мышления, ООО «Попурри», Минск].

Gaberkorn I.I., (2013), Podgotovka budushchikh uchiteley nachal'nykhklassov $k$ razvitiyu tvorcheskikh sposobnostey mladshikh shkol'nikov v protsesse obucheniya: Avtoref. ... kand. ped. nauk: 13.00.04, Kherson, [Габеркорн И.И., (2013), Подготовка будущих учителей начальных классов к развитию творческих способностей младших школьников в процессе обучения: Автореф. ... канд. пед. наук: 13.00.04, Херсон].

Gatanovyu.B., (1996), (Po metodike Dzh Gilforda IDZH. Renzulli) Kurs razvitiya tvorcheskogo myshleniya: Pervyy god obucheniya (dlya detey 6-10 let), DP «Imaton», Sankt Peterburg, [Гатанов Ю.Б., (1996), (По методике Дж Гилфорда и Дж. Рензулли) Курс развития творческого мышления: Первый год обучения (для детей 6-10 лет), ДП «Иматон», Санкт Петербург].

Khutorskoy A.V., (2000), Razvitiye odarennosti shkol'nikov: Metodikaproduktivnogo obucheniya: Posobiye dlya uchitelya, Gumanit. Izd. Tsentr VLADOS, Moskva, [Хуторской А.В., (2000), Развитие одаренности школьников: Методика продуктивного обучения: Пособие для учителя, Гуманит. Изд. Центр ВЛАДОС, Москва].

Kunenkol.A., (2000), Korrektsionno-reabilitatsionnyye aspekty muzykal'noesteticheskoy deyatel'nosti slepykh mladshikh shkol'nikov [v:] Didakticheskiye i sotsial'no-psikhologicheskiye aspekty korrektsionnoy raboty $v$ spetsial'noy shkole: metod. sb., Vyp. 1, ID APN Ukrainy, Kiyev, [Куненко Л.А., (2000), Коррекционно-реабилитационные аспекты музыкальноэстетической деятельности слепых младших школьников [в:] Дидактические и сочиально-психологические аспекты коррекционной работы в специальной школе: метод. сб, Вып. 1, ИД АПН Украины, Киев].

Makhmutov M.I., (1975), Problemnoye obucheniye. Osnovnyye voprosy teorii, Moskva, [Махмутов М.И., (1975), Проблемное обучение. Основные вопросы теории, Москва].

Molyako V.A., (1995), Psikhologiya det.skoy odarënnosti, Znaniye, Kiyev, [Моляко В.А., (1995), Психология детской одарённости, Знание, Киев]. 
Nafikova L.A., (2008), Realizatsiya sotsial'noaktivnogo potentsiala slabovidyashchikh mladshikh shkol'nikov sredstvami muzykal'nogo iskusstva:eksperimental'nyye dannyye, [v:] Didakticheskiye i sotsial'nopsikhologicheskiye aspekty korrektsionnoy raboty $v$ spetsial'noy shkole: Nauk.-metod. sb., Vyp. 10, Kiyev, [Нафикова Л.А., (2008), Реализация социально активного потенциала слабовидящих младших школьников средствами музыкального искусства: экспериментальные данные [в:] Дидактические и сочиально-психологические аспекты коррекционной работы в специальной школе: Наук.метод. сб., Вып. 10, Киев].

Sereda I.A., (2011), Razvitiye tvorcheskikhsposobnostey uchashchikhsya mladshego shkol'nogo vozrasta $v$ protsesse fizicheskogo vospitaniya: Avtoref. ... kand. ped. nauk: 13.00.07, Ternopol'. [Середа И.А., (2011), Развитие творческих способностей учащихся младшего школьного возраста в процессе физического воспитания: Автореф. ... канд. пед. наук: 13.00.07, Тернополь].

Sineva Ye.P., (2008), Tiflopsikhologiya, Znaniye, Kiyev, [Синева Е.П., (2008), тифлопсихология, Знание, Киев].

Sinevaye.P., (2012), Osobennosti razvitiya ivospitaniya lichnosti pri glubokikh narusheniyakh zreniya: monografiya, Izd-vo NPUIMENI M.P. Dragomanova, Kiyev, [Синева Е.П., (2012), Особенности развития и воспитания личности при глубоких нарушениях зрения: монография, Изд-во НПУ имени М.П. Драгоманова, Киев].

Sologub A., (2006), Tekhnologiya kreativnogo obucheniya, „Upravleniye obrazovaniyem", № 11 (131) iуun', [Сологуб А., (2006), Технология креативного обучения, „Управление образованием”, № 11 (131) июнь].

Torrance E.P., (1988), The nature of creativity as manifestin the testing, [in:] Sternberg R., Tardif T. (eds.), The nature of creativity, Cambridge.

Vorob'yeva T.V., (2014), Formirovaniya kreativnykh sposobnostey mladshikhshkol'nikov v protsesse resheniya uchebnykh zadach: Avtoref. ... kand. ped. nauk: 13.00.09, Ternopol'. [Воробьева T.В., (2014), Формирования креативных способностей младших школьников в прочессе решения учебных задач: Автореф.... канд. пед. наук: 13.00.09, Тернополь].

Vygotskiy L.S., (1991), Voobrazheniye $i$ tvorchestvo $v$ detskom vozraste, Moskva. [Выготский Л.С., (1991), Воображение и творчество в детском возрасте, Москва]. 